\title{
LA RETROACTIVIDAD PROCESAL PENAL EN MÉXICO. UN ENFOQUE DESDE EL DERECHO CONSTITUCIONAL Y CONVENCIONAL
}

\author{
The criminal procedural retroactivity in México \\ A focus from Constitutional and Conventional Law \\ Rodolfo Rafael ELIZALDE CASTANEEDA* \\ Jorge Alejandro VÁSQUEZ CAICEDO **
}

Sumario:

I. Introducción II. Marco teórico-conceptual sobre los derechos humanos y la retroactividad procesal penal III. La retroactividad procesal penal en beneficio del reo en el derecho constitucional y convencional IV. Conclusiones

Resumen: En México la aplicación de la retroactividad procesal penal en beneficio del reo, dentro de cada proceso penal, se ha sometido a la interpretación de cada órgano judicial encargado de su aplicación, optando como regla general por su inaplicabilidad. Eso explica el que no exista un criterio estándar en dicha aplicación, sino solamente un principio positivista que se ve reflejado en algunas de las tesis jurisprudenciales que se analizan en este texto. Se presenta el resultado de un análisis lógico-jurídico, jurisprudencial y doctrinal, que nos permita ir más allá de los argumentos positivistas, con base en las reformas constitucionales en Amparo y Derechos Humanos en México del 6 y 10 de junio del 2011 y, sobre todo, con base en la interpretación del principio pro homine, así como también en algunas sentencias emitidas por los tribunales internacionales de derechos humanos.

Palabras clave: Retroactividad, Retroactividad procesal penal, Derecho constitucional, Derecho convencional, Derechos humanos, principio pro homine

Abstract: In Mexico, the application of criminal procedural retroactivity for the benefit of the inmate, within each criminal process, has been submitted to the interpretation of each judicial body in charge of its application, opting as a rule for its inapplicability. This explains why there is no standard criterion in this application, but only a positivist

* Profesor-Investigador de Tiempo Completo de la Facultad de Derecho de la Universidad Autónoma del Estado de México. E-mail: rodolfoelizaldecas@yahoo.com.mx

** Alumno de la Maestría en Derecho con área terminal en Justicia Constitucional de la Facultad de Derecho de la Universidad Autónoma del Estado de México. E-mail_vvasquezcaicedo@hotmail.com 
principle that is reflected in some of the jurisprudential theses analyzed in this paper. Therefore, what is intended with this research is to perform a logical-legal, jurisprudential and doctrinal analysis, which allows us to go beyond the positivist arguments, based on the constitutional reforms in Amparo and Human Rights in Mexico of 6 and 10 June 2011 and, above all, based on the interpretation of the pro homine principle, as well as in some sentences issued by international human rights courts.

Keywords. Retroactivity, Criminal procedural retroactivity, Constitutional Law, Conventional Law, Human Rights, pro homine principle

\section{Introducción}

El objetivo principal de esta investigación fue conocer la evolución que ha tenido en México el principio de retroactividad procesal penal en beneficio del reo, sobre todo, a partir de las reformas constitucionales en materias de amparo ${ }^{1}$ y derechos humanos ${ }^{2}$ del 6 y 10 de junio de 2011, con base en la dogmática constitucional, la interpretación de los tribunales del poder judicial de la federación, las posturas doctrinales y legales, así como en los tratados internacionales suscritos por el estado mexicano y en algunas sentencias de los tribunales internacionales de derechos humanos. Así como la influencia que tuvo en éstas el principio pro homine.

Como podemos observar, nos referimos a dos momentos en la historia de nuestro país, antes de las reformas constitucionales mencionadas y, después de ellas. Por ese motivo, resulta relevante el estudio que aquí proponemos, pues no es lo mismo la retroactividad penal como principio que surge históricamente de la mano del estado constitucional de derecho, que la retroactividad penal vista con los lentes de las mencionadas reformas, pues a partir de éstas surgió un nuevo paradigma en la materia de derechos humanos al alcance de todos los operadores jurídicos ${ }^{3}$, que cambiaría, sigue cambiando y continuará cambiando por muchos años, para utilizar las palabras de Silva Meza, el modo de administrar justicia ${ }^{4}$, así como el rumbo del derecho constitucional y convencional.

Para darnos cuenta de esta situación, basta con volver la mirada al primer párrafo del artículo $1^{\circ}$ de la Constitución Política de los Estados Unidos Mexicanos (CPEUM), que refiere que, todas las personas gozarán de los derechos humanos reconocidos en esta Constitución y en los tratados internacionales de los que el Estado Mexicano sea parte,

Reforma constitucional del 6 de junio de 2011, en materia de derecho de amparo publicada en el Diario Oficial de la Federación (DOF), [en línea], disponible en: http://www2.scjn.gob.mx/red/constitucion/6Junio.html, [consultado el 5 de septiembre de 2018].

2 Reforma constitucional del 10 de junio de 2011, en materia de derechos humanos publicada en el DOF, [en línea], disponible en: http://www2.scjn.gob.mx/red/constitucion/10Junio.html,_[consultado el 5 de septiembre de 2018].

3 Cfr. Carbonell, Miguel y Salazar, Pedro (coords. 2012), La Reforma Constitucional de Derechos Humanos. Un nuevo paradigma, Porrúa-UNAM, México; FerRajoli, Luigi (2006), Sobre los Derechos Fundamentales y sus Garantías, Trad. Miguel Carbonell, Antonio de Cabo Gerardo Pisarello, Universidad de Roma III, Italia, Comisión Nacional de los Derechos Humanos, México.

4 Silva Meza, Juan N. (s.a.), "El Control de Convencionalidad y dialogo jurisprudencial. Una nota", [en línea], disponible en: http://angelduran.com/docs/Cursos/DAJDDHH16/mod04/L03-05-Juan-Silva-Meza-Revista-Pro-Homine-CC-aDE.pdf,_[consultado el 5 de septiembre de 2018]. 
así como de las garantías para su protección $[\ldots]^{5}$. Esta disposición nos llevó a revisar, no solamente la actuación de los tribunales federales sino, igualmente, algunos de los tratados internacionales que ha suscrito el estado mexicano, así como la actuación de los tribunales internacionales de derechos humanos sobre la figura de la retroactividad o irretroactividad procesal penal.

Este estudio se justifica en primer lugar, toda vez que en la literatura jurídica no encontramos ningún antecedente igual o parecido $\mathrm{y}$, menos, tan actual; en segundo lugar, tradicional e históricamente la omisión de la aplicación retroactiva de la norma procesal penal -principalmente del principio in dubio pro-reo o in dubio pro imputado-, por parte de los tribunales en México, ha sido la norma general que han marcado los tribunales federales a través de diversos criterios jurisprudenciales. Por lo que resultará interesante, para el mundo jurídico, ver la forma como ha venido evolucionando ese principio a partir de las mencionadas reformas en el contexto del derecho constitucional y del convencional, dentro de la delimitación que propusimos de acuerdo con Zaffaroni hay una estrecha relación entre el derecho penal y los derechos humanos ${ }^{6}$.

En torno y posterior a las mencionadas reformas se fue desarrollando un importante bagaje doctrinal, así como cambios constitucionales, legales y jurisprudenciales, tanto en el ámbito nacional como en el internacional.

Consideramos que postura prohibicionista que sobre el principio de retroactividad estableció la Suprema Corte de Justicia de la Nación (SCJN) se contrapone y es violatoria del propio derecho constitucional y convencional que surgió a partir de las mencionadas reformas; tal es el caso del ya citado artículo $1^{\circ}$ y del artículo 14 de nuestra carta magna, de los tratados internacionales de los que el estado mexicano forma parte y, en especial, de la Convención Americana sobre Derechos Humanos ${ }^{7}$ (CONVENCIÓNADH), la cual fue ratificada por México el 3 de febrero de $1981^{8}$ y publicado en el DOF el 7 de mayo de $1981^{9}$. Nuevamente citado artículo $1^{\circ}$, segundo párrafo de nuestra código supremo, se adoptó el principio pro homine, el cual señala: Las normas relativas a los derechos humanos se interpretarán de conformidad con esta Constitución y con los tratados internacionales de la materia favoreciendo en todo tiempo a las personas la protección más amplia ${ }^{10}$; por su parte, el artículo 14 en sus primero y segundo párrafo contempla los principios de legalidad, de retroactividad, de seguridad jurídica y debido proceso, A ninguna ley se dará efecto retroactivo en perjuicio de persona alguna, Nadie podrá ser privado de la libertad o de sus propiedades, posesiones o derechos, sino mediante juicio seguido ante los tri-

\footnotetext{
Constitución Política de los Estados Unidos Mexicanos del 5de febrero de 1917, [en línea], disponible en: http://www.diputados.gob.mx/LeyesBiblio/, [consultada el 8 de septiembre de 2018].

${ }^{6}$ Cfr. ZafFaroni, Eugenio Raúl (2000), "Derechos Humanos y sistemas penales en América Latina”, [en línea], disponible en: Criminología crítica y control social. El poder punitivo del Estado, Ed. Juris, Argentina, pp. 63-74.

7 Convención Americana Sobre Derechos Humanos, noviembre 1969, [en línea], disponible en: https:// www.oas.org/dil/esp/tratados_b-32_convencion_americana_sobre_derechos_humanos.htm, [consultado el 8 de septiembre de 2018].

${ }_{8}^{8}$ México depositó el instrumento de ratificación correspondiente en la Secretaria General de la OEA, el 24 de marzo de 1981.

9 Compendio de tratados internacionales sobre derechos humanos (2013), 1ª Ed. Ediciones Jurídicas LopMOn, México. p. 247.

${ }^{10}$ El énfasis es nuestro.
} 
bunales previamente establecidos, en el que se cumplan las formalidades esenciales del procedimiento y conforme a las Leyes expedidas con anterioridad al hecho.

Por otra parte, en la citada CONVENCIÓNADH, igualmente se alude a los mencionados principios en su artículo 9 [...] Si con posterioridad a la comisión del delito, la ley dispone la imposición de una pena más leve, el delincuente se beneficiará de ello ${ }^{11}$. También se refiere a dichos principios la Declaración Universal de los Derechos Humanos (DUDH) del 10 de diciembre de $1948^{12}$, en su artículo 11, numeral 2: Nadie será condenado por actos $u$ omisiones que en el momento de cometerse no fueron delictivos según el Derecho nacional o internacional. Tampoco se impondrá pena más grave que la aplicable en el momento de la comisión del delito.

De lo anterior, surgieron las interrogantes que guiaron este trabajo: ¿A partir de las reformas constitucionales en México del 6 y 10 de junio de 2011, los tribunales federales están obligados a aplicar retroactivamente la ley procesal penal en beneficio del reo? ¿La omisión de la aplicación retroactiva de la ley procesal penal en beneficio del reo, por parte de los tribunales federales en México, se contrapone al derecho constitucional y convencional surgido a partir de las reformas constitucionales del 6 y 10 de junio de 2011? ¿La omisión de la aplicación retroactiva de la ley procesal penal en beneficio del reo viola el principio pro homine?

La hipótesis que formulamos consistió en las reformas constitucionales del 6 y 10 de junio de 2011 establecieron, en México, un nuevo paradigma en materia de derechos humanos y junto con el principio pro homine dieron un giro histórico al principio de retroactividad penal contemplado solamente en materia sustantiva y en la pena, desde los orígenes del Estado liberal, pasando por el Estado social, hasta llegar al Estado constitucional democrático y social. Por lo que, a partir de estas reformas, derivado de la influencia también del derecho convencional, inicia la aplicación, de manera muy despacio, lenta y pausada, del principio de retroactividad en materia procesal penal en beneficio del reo.

La teoría del garantismo penal de Luigi Ferrajoli guio este trabajo, pues derivado de la protección a los derechos y libertades de la persona, sin duda alguna, impregna el debido proceso, el proceso penal y la jurisprudencia en materia de retroactividad tanto en el plano interno como en el plano internacional. Esta fue la manera en que se pudo analizar la aplicación retroactiva de la ley procesal penal en beneficio del reo en México. Por su parte, el desarrollo metodológico de este trabajo se basó en el análisis de diversas tesis de jurisprudencia dictadas por los tribunales federales mexicanos, a fin de poder conocer la evolución que ha tenido el principio de retroactividad procesal penal en beneficio del reo, con base en los métodos deductivo, analítico, sintético, descriptivo y comparativo. Asimismo, utilizamos como técnicas de investigación la documental derivada del estudio de libros, artículos científicos, tratados internacionales, etc.

\footnotetext{
${ }^{11}$ Convención Americana, op. cit. nota 7. El énfasis es nuestro.

${ }^{12}$ Declaración Universal de los Derechos Humanos. Diciembre 1948, [en línea], disponible en: http://www. onunoticias.mx/biblioteca/documentos-importantes/declaracion-universal-de-los-derechos-humanos/, [consultado el 10 de septiembre de 2018].
} 


\section{Marco teórico-conceptual sobre los derechos humanos y la retroactividad procesal penal}

Si bien se pudiera pensar que los derechos humanos han existido a la par del propio origen de la humanidad, lo cierto es que a partir de la Declaración de los Derechos del Hombre y del Ciudadano ${ }^{13}$, surgida en Francia el 26 de agosto de 1789, generó un impacto mundial, que además de reconocerlos positivamente los ubicó en la cúspide del estado de derecho constitucional garantista ${ }^{14}$. Su evolución ha sido internacional y progresiva, anteriormente, nos dicen Fix Zamudio y Valencia Carmona que, se consideraban a los derechos humanos un asunto doméstico, eran cuestiones que estaban reservadas a cada gobierno respecto de sus nacionales ${ }^{15}$, sin embargo, su auge se dio a partir de la segunda guerra mundial, con la creación de la Organización de las Naciones Unidas (ONU) y reflejada en la referida DUDH ${ }^{16}$.

En México, los derechos humanos fueron reconocidos como garantías individuales hasta la promulgación del texto constitucional de $1857^{17}$, y posteriormente formarían parte, con ese mismo nombre, del citado texto constitucional vigente de $1917^{18}$.

Para Silva Meza, los derechos humanos son: Prerrogativas mínimas que todo miembro de la especie humana, por su propia naturaleza, debe gozar, y cuyo respeto y observancia deben ser garantizados por el Estado en todo tiempo y lugar, pues a través de ellas se concretan las exigencias de la dignidad humana ${ }^{19}$, y merced a la integración del principio pro homine en nuestro código supremo, Carbonell refiere que se entiende por éste, cuando existan distintas interpretaciones posibles de una norma jurídica, se deberá elegir aquella que más proteja al titular de un derecho humano ${ }^{20}$.

Cabe mencionar que, la convencionalidad de acuerdo al propio Carbonell es la consecuencia directa del deber de los Estados de tomar todas las medidas que sean necesarias para que los tratados internacionales que han firmado se apliquen cabalmente ${ }^{21}$; de lo que se entiende que, el Estado al contraer obligaciones de derecho y suscribir un tratado internacional con otro estado o con algún organismo internacional tiene que hacer efectivas en la legislación nacional las disposiciones internacionales que ha firmado. Así

$\overline{{ }^{13} \text { GellineK, Georg }}$ (2000), La Declaración de los Derechos del Hombre y del Ciudadano, Traducción y estudio preliminar de Adolfo Posada, México, Universidad Nacional Autónoma de México.

${ }^{14} C f r$. Ferrajoli (2011), "El constitucionalismo garantista. Entre paleo-iuspositivismo y neo-iusnaturalismo". Doxa, Cuadernos de Filosofía del Derecho, 34, pp.311-360, [en línea], disponible en: https://doxa. ua.es/article/view/2011-n34-constitucionalismo-principialista-y-constitucionalismo-garantista, [consultado el 10 de septiembre de 2018].

${ }^{15}$ Fix-Zamudio, Héctor y Valencia Carmona, Salvador (2009), Derecho Constitucional Mexicano y comparado, $6^{\text {a }}$ ed. México, UNAM, Porrúa, p. 431.

${ }^{16}$ Declaración Universal de los Derechos Humanos, op. cit. nota 12.

${ }^{17}$ Cfr. Tena Ramírez, Felipe (2008), Leyes Fundamentales de México 1808-2005. 25a ed. México, Porrúa.

${ }^{18}$ Ídem.

${ }^{19}$ Silva Meza, Juan N. (Coord. 2018), "Derechos Humanos parte general” en: Compilación y Sistematiza-

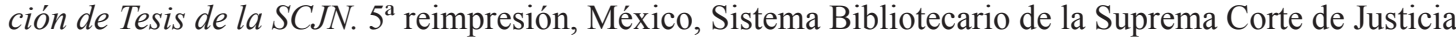
de la Nación, p. 5.

${ }^{20}$ CARBonell, Miguel (2015), El ABC de los derechos humanos y del Control de Convencionalidad, $2^{\text {a }}$ Ed. México, UNAM, Porrúa, p. 97.

${ }^{21}$ Idem. 
se desprende de la Convención de Viena sobre el Derecho de los Tratados ${ }^{22}$, la cual en su artículo 26 establece el principio de derecho internacional, Pacta sunt servanda, que consiste en que, Todo tratado en vigor obliga a las partes y debe ser cumplido por ellas de buena fe. Mientras que, en su artículo 27, por lo que se refiere al derecho interno y la observancia de los tratados establece, Una parte no podrá invocar las disposiciones de su derecho interno como justificación del incumplimiento de un tratado.

Vinculando los derechos humanos, el principio pro homine, la convencionalidad y constitucionalidad al derecho penal, tenemos la teoría del garantismo de Luigi Ferrajoli, la cual:

propone una nueva concepción de democracia constitucional, partiendo de dos divisiones: democracia formal y democracia sustancial. La primera está relacionada con la manera en que se toman las decisiones políticas y la segunda está ligada al respeto y protección de los derechos fundamentales. El propósito principal del sistema garantista es dotar de eficacia y pleno cumplimiento a los derechos fundamentales. ${ }^{23}$

En resumen, aquí destacamos que, a partir de las precitadas reformas constitucionales se ha dado mayor énfasis a diversos derechos que implican mayor actividad del estado y de los órganos jurisdiccionales que están a su cargo, a fin de garantizar la protección a los derechos humanos y sus garantías, protegiendo en amplio rango a la dignidad humana.

Por otra parte, el máximo tribunal de nuestro país ha definido la retroactividad: una ley es retroactiva cuando vuelve al pasado para cambiar, modificar o suprimir derechos individuales ya adquiridos ${ }^{24}$. De la misma manera ha confirmado que, la aplicación retroactiva de la ley es permisible aplicarla en beneficio de la persona, en particular de los procesados y sentenciados por un delito ${ }^{25}$, de donde apreciamos que su definición en realidad es la misma que establece el artículo 14 Constitucional, la cual, insistimos, no hace distinción en cuanto a qué tipo de normas se prohíbe o se permite.

En término de lo antes expuesto, podemos señalar que la retroactividad, trata de un derecho que es oponible a todas las autoridades (legislativas, ejecutivas y judiciales), para toda materia que pueda poner en riesgo un derecho sustantivo 'de imposible reparación', como pueden ser la vida, la propiedad, la seguridad o la igualdad ${ }^{26}$.

Por su parte, Roubier define a la retroactividad cuando las normas se aplican a hechos consumados bajo el imperio de una ley anterior, y a situaciones jurídicas en curso, por lo que toca a los efectos realizados antes de la iniciación de la vigencia de la nueva ley ${ }^{27}$, con ello podemos resumir que la retroactividad significa aplicar una ley o norma posterior a un hecho que, en el momento de haber ocurrido, no se encontraba vigente.

\footnotetext{
${ }^{22}$ Convención de Viena sobre el Derecho de los Tratados, publicada en el DOF, el 14 de febrero de 1975, [en línea], disponible en: http://www.ordenjuridico.gob.mx/TratInt/I1.pdf, (consultado el 12 de septiembre de 2018).

${ }^{23}$ Aguilera Portales, Rafael Enrique y López Sánchez, Rogelio (2011), Los derechos fundamentales en la teoría garantista de Luigi Ferrajoli, México, Instituto de Investigaciones Jurídicas de la UNAM, p. 55.

${ }^{24}$ Guevara B. José A. (2013), "La prohibición de la aplicación retroactiva de la ley", en: Derechos Humanos en la Constitución: Cometarios de jurisprudencia constitucional e interamericana, tomo II, México, Suprema Corte de Justicia de la Nación, p. 1439.

${ }^{25}$ Idem.

${ }^{26}$ Idem, p. 1447.

${ }^{27}$ García Máynez, Eduardo (2013), Introducción al Estudio del Derecho, 64a ed. México Porrúa.
} 
Asimismo, Fix-Zamudio y Fix-Fierro nos indican que la retroactividad se presenta: cuando afectan situaciones o derechos que han surgido con apoyo en disposiciones legales anteriores, o cuando lesionan efectos posteriores de tales situaciones o derechos ${ }^{28}$.

Hacemos hincapié en que, la legislación nacional en su ya citado artículo 14 constitucional al referirse a la retroactividad, hablan de la ley o norma en general, sin hacer algún tipo de distinción en cuanto a qué tipo de norma se trata, es decir, no indica si únicamente las de contenido sustantivo, o también las de contenido adjetivo, por lo que se entiende que contempla todo tipo de normas jurídicas. Esto es, aquí cabe tener presente la locución latina, Ubi lex non distinguit, nec nos distinguere debemus: Donde la ley no distingue, nosotros no debemos distinguir.

Ante esta situación, debemos señalar que existen normas sustantivas y normas adjetivas, cuya diferencia radica en que las primeras hacen referencia a cualquier contenido normativo que se encarga de proteger los derechos inherentes de las personas y que regulan tanto sus derechos humanos como sus garantías constitucionales; $y$, por cuanto hace a las segundas, se encargan de regular exclusivamente el proceso, es decir, sus etapas hasta llegar a resolver la litis planteada ante el juzgador. En estas ideas seguimos a Ortega y Gasset, quien señala ${ }^{29}$ :

1. Constituyen el llamado Derecho material, sustantivo, determinador o sustancial, las normas jurídicas que tienen una finalidad propia y subsistente por sí, fijando la regla de conducta, señalando las facultades y deberes de cada cual.

2. Integran el Derecho adjetivo, sancionador, formal, instrumental, de garantía o Derecho para el Derecho, las normas jurídicas que tienen una existencia dependiente y subordinada, pues sólo se proponen facilitar los medios para que se cumpla la regla establecida, garantizando el respeto de las facultades y deberes atribuidos por el Derecho sustantivo.

Resumiendo, las normas adjetivas son las que regulan la aplicación de otras normas de contenido sustantivo y estas mismas son las que solamente pueden ser aplicadas por el órgano jurisdiccional en las etapas del proceso, es decir, son las que integran las fases del procedimiento y que disciplinan la actividad jurisdiccional del Estado, a diferencia de las normas sustantivas, que son las que conceden derechos o establecen obligaciones (facultades y deberes), regulando cuestiones de fondo, de lo que se puede establecer que es posible que existan normas adjetivas, pero de contenido sustancial, que son aquellas que si bien es cierto regulan cuestiones de forma dentro del procedimiento, también lo cierto es que al aplicarla su finalidad no es meramente procesal, sino que también afecta derechos sustantivos. Un ejemplo de esta situación, la constituye el artículo 107 fracción $\mathrm{V}$, de nuestro máximo ordenamiento ${ }^{30}$.

Con todo lo anterior, podemos establecer que la retroactividad procesal penal consiste en aplicar una ley o norma procesal posterior a un hecho que, en el momento de haber

\footnotetext{
${ }^{28}$ Fix-Zamudio, Héctor y Fix-Fierro, Héctor, en: Miguel Carbonell (Coord.) (2009), “Artículo 14”, en Constitución Política de los Estados Unidos Mexicanos, comentada y concordada, 29a ed. México, Porrúa, Tomo I, p. 275.

${ }^{29}$ Magaña de la Mora, Juan Antonio (2004), El catálogo de delitos graves como norma sustantiva y no adjetiva, Supremo Tribunal de Justicia del Estado de Michoacán, Michoacán, México, pp. 3-4.

${ }^{30}$ Cfr. Reforma constitucional del 6 de junio de 2011, op. cit. nota 1.
} 
ocurrido, no se encontraba vigente tal ley o norma, en materia criminal. Y, que a partir de las precitadas reformas constitucionales y atendiendo al principio pro homine, se deberá de aplicar la ley retroactiva más benéfica a la persona, sin hacer distinción sobre si se trata de una norma de carácter sustantivo o adjetivo. O, como lo refiere Silva Meza, [...] teniendo como siempre como criterio de ponderación de normas, el principio pro persona que, como sabemos, determina que la norma que mejor protege y da contenido a un derecho reconocido debe ser tomada como base para la interpretación judicial en el caso concreto ${ }^{31}$.

\section{La retroactividad procesal penal en beneficio del reo en el derecho constitucional y convencional}

El principio moderno de legalidad y retroactividad, tal y como hoy lo conocemos, nace con el estado constitucional de derecho, así se desprende de los artículos 7 y 8 de la antecitada Declaración de los Derechos del Hombre y del Ciudadano ${ }^{32}$. Por su parte, el maestro Tena Ramírez en su ya mencionada obra, Leyes Fundamentales de México $1808-2005^{33}$, alude igualmente a este principio desde los orígenes de la nación mexicana en los principales documentos constitucionales, como son: La Constitución Política de la Monarquía Española, también conocida como Constitución de Cádiz, en sus artículos 286 y 287; El Acta Constitutiva de la Federación Mexicana del 31 de enero de 1824, en su artículo 19; La Constitución de los Estados Unidos Mexicanos del 4 de octubre de 1824, en su artículo 148; Las Bases y Leyes Constitucionales de la República Mexicana de 1836, Primera, articulo 2, Frac. V; La Constitución Federal de los Estados Unidos Mexicanos del 5 de febrero de 1857, en su artículo 14.

Observando que, en realidad, históricamente el principio de retroactividad no ha cambiado, pues es el mismo que en la actualidad contiene el precitado artículo 14 de la carta magna en vigor. De este precepto, se desprende el carácter terminante y mandatorio de su contenido, estableciendo la regla general de que no se deberá dar efecto retroactivo a ninguna ley -sin hacer distinción sobre qué tipo de ley, ya sea sustantiva o adjetiva-, en perjuicio de las personas; igualmente, establece la regla de que para que alguien sea privado de su libertad, propiedades, posesiones o derechos, deberá ser mediante un juicio, que deberá seguirse ante los tribunales establecidos, cumpliendo las formalidades esenciales del procedimiento y conforme a las leyes expedidas con anterioridad el hecho. Este último párrafo, se refiere a lo que hoy se conoce en nuestro ordenamiento jurídico como derecho humano al debido proceso.

Sin embargo, desde el año de 1993 los tribunales federales han argumentado que tanto la jurisprudencia, como la doctrina y el derecho positivo, coinciden en que el principio de irretroactividad contemplado por el antecitado precepto constitucional se refiere solamente al derecho sustantivo y a la pena, pero no al derecho adjetivo, puesto que éste se rige solamente por la ley vigente. Esto se desprende de la Tesis de Jurisprudencia Penal, 215196 con el rubro de RETROACTIVIDAD DE LA LEY PENAL EN BENEFICIO

\footnotetext{
${ }^{31}$ Silva MeZA, op. cit. nota 4, p. 16.

${ }^{32}$ GellineK, Georg, op. cit. nota 14.

${ }^{33}$ Cfr. Tena Ramírez, Felipe, op. cit. nota 18.
} 
DEL REO. NO OPERA EN MATERIA ADJETIVA O PROCEDIMENTAL ${ }^{34}$, que en su parte conducente dice:

\begin{abstract}
Aun cuando es exacto que el principio de la irretroactividad recogido en el párrafo primero del artículo 14 de la Constitución Federal tiene como excepción en materia penal aquellos casos en que la nueva ley es más benigna para el reo, lo que ha sido reconocido en forma unánime por la jurisprudencia, la doctrina y el derecho positivo; también lo es que tales hipótesis excepcionales, sin duda alguna, se refieren al aspecto sustantivo del delito y de la pena, más no al adjetivo o procedimental, pues es de explorado derecho que el proceso se rige por la ley vigente en el momento en que cada diligencia se desarrolla, por lo que sería absurdo y contrario al principio de seguridad jurídica, pretender que las actuaciones realizadas con anterioridad a la vigencia de la nueva ley carezcan de todo valor probatorio por no ajustarse a los nuevos criterios adoptados por el legislador para su práctica, ya que de ser así los Órganos Jurisdiccionales no tendrían ningún soporte jurídico para establecer en sus sentencias que las autoridades investigadoras debieron observar en la práctica de aquellas diligencias requisitos que no existían en el momento en que se efectuaron.
\end{abstract}

Posteriormente, los mencionados tribunales continuaron fijando la misma postura respecto a la irretroactividad en materia penal adjetiva en beneficio del reo, como igualmente se desprende del siguiente criterio, RETROACTIVIDAD. APLICACIÓN IMPROCEDENTE DE LA LEY PROCESAL PENAL ${ }^{35}$, emitido en el mismo año de 1993. Dos años después, en 1995 los propios tribunales emitieron una tesis aislada que dejaba entrever que las leyes de procedimiento además de contener disposiciones que afectan solamente a las partes, también contienen disposiciones de la ley sustantiva, por lo que, concluye, que aquellas no deben aplicarse cuando lesionan derechos adquiridos. Por lo que, leyendo a contrario sensu, nosotros consideramos que cuando no se lesionan tales derechos si son factible de aplicarse y sobre todo cuando en materia penal son en beneficio del reo y con las mismas se lesionan derechos sustantivos ${ }^{36}$. En 1998 se emite otro criterio insistiendo en la no existencia de la retroactividad en materia procesal, RETROACTIVIDAD DE LAS LEYES PROCESALES. NO EXISTE POR REGLA GENERAL ${ }^{37}$.

Para el año 2000, al emitir la Tesis Aislada 190801, de rubro: LIBERTAD PROVISIONAL BAJO CAUCIÓN. DEBE APLICARSE LA LEY MÁS FAVORABLE AL PROCESADO, siguió insistiendo en ese discurso, pero, ahí mismo acepta que si la norma adjetiva vigente al momento de los hechos beneficia al procesado y con motivo de una reforma le perjudica, se concluye que debe aplicarse el beneficio constitucional.

La Suprema Corte de Justicia de la Nación ha establecido diversos criterios en el sentido de que tratándose de leyes procesales no opera el principio de retroactividad en favor del reo; sin embargo, si el procesado solicita el beneficio consti-

\footnotetext{
${ }^{34}$ Tesis de Jurisprudencia Penal, 215196. 1o. J/6, Gaceta del Semanario Judicial de la Federación, Octava Época, Tribunales Colegiados de Circuito, Núm. 68, agosto de 1993. Pág. 91.

35 Tesis: 215663, Tribunales Colegiados de Circuito. Octava Época, Semanario Judicial de la Federación, Tomo XII, agosto de 1993, Pág. 554.

${ }^{36}$ Tesis Aislada 205234: IRRETROACTIVIDAD DE LAS LEYES DE PROCEDIMIENTO. VI.1o.2 K. Semanario Judicial de la Federación y su Gaceta, Novena Época, Tribunales Colegiados de Circuito, Tomo I, mayo de 1995, Pág. 379.

${ }^{37}$ Tesis: VI.2o. J/140. Tribunales Colegiados de Circuito, Novena Época. Semanario Judicial de la Federación y su Tomo VIII, Julio de 1998, Pág. 308.
} 
tucional de libertad provisional bajo caución, el juzgador no sólo debe tomar en cuenta la norma adjetiva que indica el procedimiento y requisitos de procedencia, sino también la norma sustantiva que contiene la conducta típica y la penalidad correspondiente, siendo que dicha norma será determinante para la concesión del beneficio; por tanto, si la norma adjetiva relativa a ese derecho, vigente al momento de los hechos le beneficia al solicitante y con motivo de una reforma le perjudica, debe aplicarse la ley sustantiva en beneficio del gobernado conforme a lo establecido en el artículo 14 constitucional y concederse el beneficio de la libertad provisional bajo caución. ${ }^{38}$

Huerta en su artículo, Retroactividad en la Constitución coincide con el contenido de esta tesis ${ }^{39}$. Con base en esta última tesis transcrita, podemos decir que el discurso de los tribunales federales empieza a cambiar en el sentido de que sí es factible aplicar una ley adjetiva cuando sea más favorable al reo, pues la figura de la fianza se encuentra regulada por una ley adjetiva penal, aunque el argumento de peso lo fue que esa figura tenía directamente que ver con la libertad que es un derecho sustantivo.

A continuación, nos referimos a la tesis por contradicción emitida en el año 2001, que sustituyó a la anterior tesis transcrita en parte, por la primera sala de la SCJN, quien determinó en la Tesis de Jurisprudencia Penal $189939^{40}$, que la libertad provisional bajo caución es un derecho sustantivo y por consiguiente sí opera la excepción contemplada en el artículo 14 constitucional, referente a la aplicación retroactiva de la ley en beneficio del reo, como se desprende de la referida tesis con el rubro: LIBERTAD PROVISIONAL BAJO CAUCIÓN. ES UN DERECHO SUSTANTIVO RESPECTO DEL CUAL RIGE LA EXCEPCIÓN CONTENIDA EN EL ARTÍCULO 14 CONSTITUCIONAL, CONSISTENTE EN LA APLICACIÓN RETROACTIVA DE LA LEY EN BENEFICIO DEL REO.

A pesar de este resquicio que se intentó abrir con la tesis en parte transcrita y que se intentó volver a cerrar en el año 2001 con la tesis por contradicción mencionada en el párrafo anterior, con el argumento de que la libertad provisional bajo caución es un derecho sustantivo -aun cuando, es de reconocido derecho que esta figura estaba regulada por una ley penal adjetiva-, durante el año 2011 los referidos tribunales federales emitieron otros criterios regresando a la posición radical, RETROACTIVIDAD DE LA LEY PENAL EN BENEFICIO DEL REO. NO OPERA EN MATERIA ADJETIVA O PROCEDIMENTAL $^{41}$, y RETROACTIVIDAD DE LAS NORMAS PROCESALES ${ }^{42}$.

De las jurisprudencias y tesis antes referidas, podemos apreciar que en realidad el criterio de la SCJN desde 1980 a la fecha, ha sido el mismo y no ha cambiado, pues se

\footnotetext{
${ }^{38}$ Tesis Aislada: 190801. I.10.P.67 P. Semanario Judicial de la Federación y su Gaceta, Novena Época. Tribunales Colegiados de Circuito, Tomo XII, diciembre de 2000, p. 1401. Esta tesis fue superada por contradicción en el año 2001, con la Tesis de Jurisprudencia Penal 189939. El énfasis es nuestro.

${ }^{39}$ Huerta, Carla (s.a.), Retroactividad en la Constitución, p. 570, [en línea], disponible en: https://archivos. juridicas.unam.mx/www/bjv/libros/5/2389/19.pdf, pp. 569-594. [consultado el 15 de septiembre de 2018].

${ }^{40}$ Tesis de Jurisprudencia Penal 189939. 1a. /J. 10/2001, Semanario Judicial de la Federación y su Gaceta, Novena Época, Primera Sala, Tomo XIII, abril de 2001. Pág. 333.

${ }^{41}$ Tesis: 1006222. 844, Tribunales Colegiados de Circuito, Octava Época, Apéndice 1917-septiembre 2011, Tomo III. Penal Segunda Parte - TCC Primera Sección - Sustantivo, Pág. 806.

${ }^{42}$ Tesis: 1012265. 978, Tribunales Colegiados de Circuito, Novena Época. Apéndice 1917-septiembre 2011. Tomo I, Constitucional 3, Derechos Fundamentales Segunda Parte - TCC Cuarta Sección - Irretroactividad de la ley y de su aplicación, Pág. 2291.
} 
ha regresado a la misma postura rígida o prohibicionista. Todo ello sin importar incluso la materia, a pesar de la precitada reforma del año 2011, a partir de la cual se intentó dar un enfoque de protección a la persona al aplicar la retroactividad procesal penal, sin embargo, se sigue justificando por virtud del derecho sustantivo y no del adjetivo, lo que se corrobora en la Ley de Amparo, ${ }^{43}$ artículo 107, fracción III, inciso b), la cual se refiere a la protección de los derechos humanos sobre violaciones procesales, pero siempre y cuando se afecten derechos sustanciales.

Ahora bien, a partir de la precitada reforma constitucional en materia de derechos humanos de 2011, específicamente en el párrafo tercero del artículo primero de nuestra carta magna, la responsabilidad de velar por la protección y garantía de los derechos humanos corresponde a todas las autoridades en el ámbito de sus competencias, que por razón de su labor tengan conocimiento de la violación de un derecho humano, como lo es la retroactividad de las normas en perjuicio de persona alguna o en su caso la omisión de la retroactividad en materia penal cuando se trata del beneficio del reo, aun siendo de carácter procesal.

En este mismo orden de ideas, también podemos decir que, como toda regla, el principio de retroactividad también tiene su excepción; esto es, mientras la regla general es que la ley no puede ser retroactiva en perjuicio de las personas, su excepción en materia penal se refiere a su aplicación cuando se trate del beneficio del reo. Sin embargo, Piqué en su trabajo titulado, Artículo 9. Principio de legalidad y retroactividad, nos dice que esa excepción surge con tintes políticos, pues se trata más bien de un principio de política criminal según el cual es inadmisible imponer o mantener una sanción cuando el hecho ya no se considera delito, o bien una pena que ha devenido desproporcionada en relación con la menor gravedad que la sociedad atribuye ahora a ese hecho ${ }^{44}$. Es decir, en materia penal, la génesis de la prohibición retroactiva de la Ley, lo fue a fin de que no se perjudicara al reo con alguna norma posterior a la comisión de algún ilícito y que le pudiera implicar mayor penalidad o una nueva penalidad que no existía al momento de los sucesos, pero dicha génesis no fue en ningún momento establecida para que el reo no se beneficiara con alguna ley o norma benéfica posterior, por lo tanto la excepción debería ser de carácter genérico, lo que queremos decir, es que en todos los casos siempre que se beneficie al reo con una ley o norma posterior, deberá ser aplicable al caso en concreto, sin hacer algún tipo de distinción entre el contenido y calidad de tal norma, principalmente en lo relativo a si es de carácter sustantivo o adjetivo. En ese mismo sentido, se pronuncia Barbosa Castillo en su obra, Principio de legalidad y proceso penal, donde sostiene que

el principio de legalidad referido al proceso penal no se limita hoy en día a la preexistencia formal de ritos y funcionarios competentes, sino que se extiende a nociones de naturaleza eminentemente procesal, pero de contenido sustancial y, además, a cuestiones estrictamente sustanciales que se han visto alternadas, complementadas y en algunos casos subordinadas por factores de carácter procesal..$^{45}$

\footnotetext{
${ }^{43}$ Ley de Amparo, Reglamentaria de los artículos 103 y 107 de la Constitución Política de los Estados Unidos Mexicanos, [en línea], disponible en: http://www.diputados.gob.mx/LeyesBiblio/pdf/LAmp_150618. pdf. [consultada el 15 de septiembre de 2018].

${ }^{44}$ PiQuÉ, María Luisa (2013), “Artículo 9. principio de legalidad y retroactividad”, en: La Convención Americana de Derechos Humanos y su proyección en el Derecho Argentino, Universidad de Buenos Aires, Argentina, p. 168.

${ }^{45}$ Barbosa Castillo, Gerardo (2005), "Principio de legalidad y proceso penal”, en: Derecho Penal y Cri-
} 
Profundizando en el tema que nos ocupa, igualmente podemos decir que el derecho humano al debido proceso establece expresamente parámetros que prohíben violar los derechos humanos del reo durante el procedimiento. En congruencia con esta posición, en el contexto internacional Llera en su investigación titulada, Doctrina del día: la ley procesal más benigna. A propósito del Código Procesal Penal de la Nación aprobado por la ley 27.063, menciona que

\section{El concepto de debido proceso es el ámbito donde se materializan los principios rec- tores del derecho procesal penal, siendo uno de éstos el de favorabilidad, principio de vital trascendencia a la hora de analizar los efectos de las diferentes normas que han tenido vigencia durante el proceso penal al que se vio sometido el individuo. ${ }^{46}$}

Por su parte, la SCJN también opta por dicho principio en términos del criterio emitido en diciembre de 2017: JURISPRUDENCIA DE LA SUPREMA CORTE DE JUSTICIA DE LA NACIÓN EN MATERIA DE DERECHOS HUMANOS Y DEBIDO PROCESO ESTABLECIDA A RAÍZ DE LA REFORMA CONSTITUCIONAL DE 10 DE JUNIO DE 2011. EN OBSERVANCIA DEL PRINCIPIO PRO-PERSONA Y A FIN DE GARANTIZAR LA PROTECCIÓN MÁS AMPLIA A LOS DERECHOS DEL GOBERNADO COMO BASE DE LA TUTELA A LA DIGNIDAD HUMANA, EL JUZGADOR DEBE ACATARLA, AUN CUANDO LOS HECHOS DELICTIVOS, LA TRAMITACIÓN DE LA CAUSA PENAL Y SU RESOLUCIÓN, HAYAN OCURRIDO CON ANTERIORIDAD A SU EMISIÓN ${ }^{47}$.

Sin embargo, como hemos visto anteriormente, en la práctica nacional existe una gran controversia en cuanto a la aplicación retroactiva de la norma procesal penal, aun siendo en beneficio del reo, pues la regla que se ha adoptado en el sistema jurídico penal mexicano es en el sentido de que debe ser inaplicable la retroactividad en normas procesales o adjetivas. Por tal motivo, insistimos que esa postura es completamente contraria a derecho, a los principios generales del derecho, a los derechos humanos y, desde luego, violatorio del principio pro homine, que debería hacerse valer en cualquier estado de derecho. Pues, como lo hemos señalado, algunas de las normas adjetivas que rigen el proceso en materia penal tienen contenido sustantivo; además, aun no teniendo contenido sustantivo y a pesar de que sea una norma meramente de carácter procesal, pero si beneficia con su aplicación al reo, debería ser aplicable al caso en concreto, a fin de tener un juicio justo.

Un ejemplo doctrinario de lo anteriormente mencionado, lo refiere el mencionado autor, Juan Antonio Magaña de la Mora ${ }^{48}$, cuando señala que:

Partiendo del supuesto que la retroactividad solo opera en materia sustantiva y no adjetiva, en algunas legislaciones estatales como en el caso de Michoacán, el catálogo de delitos graves se integra en el Código Procesal; sin embargo, no todos los dispositi-

minología, Vol 26, No 78, Universidad Externado de Colombia.

${ }^{46}$ Llera, Carlos Enrique (2015), "Doctrina del día: la ley procesal más benigna. A propósito del Código Procesal Penal de la Nación aprobado por la ley 27.063", [en línea], disponible en: http://thomsonreuterslatam.com/2015/06/doctrina-del-dia-la-ley-procesal-mas-benigna-a-proposito-del-codigo-procesal-penal-de-la-nacion-aprobado-por-la-ley-27-063-autor-carlos-enrique-llera/, [consultado el 18 de septiembre de 2018].

${ }^{47}$ Tesis: I.10.P.22 K TCC, Gaceta del Semanario Judicial de la Federación, Décima Época, t. IV, Libro 49, diciembre de 2017.

${ }^{48}$ Magaña de la Mora, op. cit., nota 30, p. 2. 
vos que aparecen en un Código Procesal tienen esa naturaleza y ese catálogo de delitos graves no tiene carácter procesal, sino que tiene mayor incidencia en la sustantiva. Por tanto, no obstante que el catálogo de delitos graves se contemple en una ley que regula el procedimiento penal, y que las normas procesales estén exentas de retroactividad, dada su naturaleza, admite retroactividad en beneficio del acusado, ya que lo contrario lo perjudica, proponiéndose que ese catálogo se ingrese en el ordenamiento sustantivo y no en el adjetivo.

De lo expuesto se desprenden dos situaciones, la primera, que no todas las normas adjetivas se encuentran en códigos o leyes procesales, existiendo la posibilidad de que una norma de esta índole se encuentre en un código o ley de contenido sustancial, como lo pueden ser los mismos códigos penales. Además, no todas las normas de contenido sustancial se encuentran exclusivamente en códigos o leyes de esta naturaleza, pues también se pueden encontrar normas sustantivas en los códigos procesales penales, apreciando que no existe un criterio unificado de la diferencia entre normas procesales y normas sustanciales.

Por lo que se refiere a la segunda situación, se observa que el autor referido solo se enfoca de manera exclusiva al catálogo de delitos graves, sin embargo, no solo acontece con tal situación, sino que puede suceder en una gran variedad de instituciones jurídicas penales, entre las que se encuentran: las normas relativas a la ejecución y sanción de penas (que incluyen los beneficios en la ejecución de la condena), los medios alternos de solución de conflictos (acuerdo reparatorio, suspensión condicional del proceso a prueba, etcétera), medios de aceleración del procedimiento (procedimiento abreviado), creación de algún recurso o alguna instancia, supresión de los careos como medio de prueba, prescripción y caducidad del delito, el ejercicio de la acción penal, entre otros; o, como incluso refiere Llera ${ }^{49}$ al citar a Blinder el principio de retroactividad de la ley más favorable comprende también a las normas procesales, como cuando un nuevo ordenamiento amplia las posibilidades de defensa, establece requisitos de procedibilidad antes no contemplados o permite una libertad bajo fianza de la que no gozaba el procesado.

La mayoría de los criterios jurisprudenciales que hemos venido citando, son precedentes o tesis aisladas, las cuales no obligan a su aplicación, a diferencia de la jurisprudencia que se establece por reiteración de criterios, por contradicción de tesis y por sustitución, las cuales de conformidad con la Ley de Amparo en su artículo $215^{50}$, sí son de aplicación obligatoria.

En el caso de la doctrina nacional, nos remitimos nuevamente a la opinión de Juan Antonio Magaña de la Mora, quien establece:

Mucho se ha cuestionado si la irretroactividad de la ley penal contempla también la Ley Procesal, en realidad la prohibición la hace de manera general, es decir se refiere a la Ley en general sin distinguir si es sustantiva o adjetiva. En efecto, ante tal generalidad deberíamos suponer que igualmente a la norma procesal se debería dar efectos retroactivos cuando se beneficie con ello al infractor; Sin embargo ello no debe ser así, habida cuenta que las normas adjetivas únicamente señalan el procedimiento, es decir, aquellas serie de actos sistematizados previamente establecidos por la Ley para llegar a una sentencia, de tal manera que sea cual fuere la reforma

\footnotetext{
${ }^{49}$ LLERA, op. cit, nota 47.

${ }^{50}$ Cfr. Ley de Amparo, op. cit. nota 44.
} 
de una ley procesal no tiene por qué afectar a un procesado y en ese sentido se ha pronunciado en reiteradas ocasiones la Suprema Corte de Justicia de la Nación y los Tribunales Colegiados (...) De tal manera que tratándose de normas procesales cuando de acuerdo a su naturaleza sean verdaderamente procesales, en nada debe afectar al infractor la entrada en vigor de una nueva norma que marque un diverso procedimiento, de ahi que la irretroactividad deba ser solamente de derecho sustantivo cuando beneficie al acusado, lo que quiere decir que en el Derecho Procesal en principio no rige la prohibición de retroactividad. La prohibición de Leyes penales retroactivas sólo rige respecto del Derecho material. ${ }^{51}$

Lo anterior explica por qué en la práctica las autoridades aplican un criterio de subsunción de la norma y de la jurisprudencia, y no un criterio en donde aplicando el principio pro homine, que cualquier persona debe gozar, le sea garantizado la protección más favorable en sus derechos humanos. Por esa razón Ferrajoli refiere:

el juez se convierte en un autómata de la ley a través de una aplicación lógico-deductiva, pero carente de razonamiento jurídico amplio y sustancial. En sentido contrario, el iuspositivismo crítico invita al juez no solamente a emitir juicios de validez de las normas jurídicas sino, aún más, a dotar y ampliar el contenido sustancial de las mismas leyes ante la existencia de lagunas, dilemas y antinomias jurídicas, evitando la arbitrariedad y procurando la discrecionalidad en los juicios de validez que emita. ${ }^{52}$

Tanto el autor mencionado, como la jurisprudencia referida y la omisión en la legislación, coinciden en que las leyes procesales solo están conformadas por facultades para ejercer derechos procesales en las etapas del procedimiento y por ello no puede existir retroactividad en ellas, porque no se priva alguna facultad o derecho sustancial, criterios respetables, pero que no compartimos, en virtud de que son criterios sumamente positivistas y que atentan contra los derechos fundamentales de las personas sujetas al procedimiento penal en su calidad de reos (imputados, procesados, sentenciados), pues como ya lo hemos indicado, existen derechos fundamentales dentro de las normas adjetivas, y aunque aparentemente no puedan existir o tener esa naturaleza de sustancial, con el simple hecho de que en algo beneficie al reo, se deberían aplicar.

Contrario a los argumentos anteriores, y a partir de la nuevamente citada reforma del 10 de junio de 2011, se han emitido por los tribunales federales algunas tesis aisladas que tienden a acercarse un poco a la postura adoptada en el presente trabajo de investigación en favor de los sentenciados, en los casos de libertad preparatoria y libertad anticipada, como podemos observar en las siguientes tres tesis publicadas en el mes de agosto de 2017, con el rubro: LIBERTAD PREPARATORIA. AL DECIDIR SOBRE EL OTORGAMIENTO DE ESTE BENEFICIO PRELIBERACIONAL -SOLICITADO POR UN SENTENCIADO EN EL SISTEMA TRADICIONAL-, EL JUEZ DEBE HACER UN EJERCICIO DE PONDERACIÓN ENTRE EL CÓDIGO PENAL FEDERAL Y LA LEY NACIONAL DE EJECUCIÓN PENAL, PARA DETERMINAR CUÁL LE GENERA MAYOR BENEFICIO ${ }^{53}$; LIBERTAD ANTICIPADA. EL PÁRRAFO SEGUNDO DEL

\footnotetext{
${ }^{51}$ Magaña de la Mora, op. cit. nota 30, pp. 7-11.

${ }^{52}$ Aguilera Portales, Rafael Enrique y LóPez Sánchez, Rogelio, op. cit. nota 24, p. 53.

${ }^{53}$ Tesis 2014837 I.7o.P.85 P TCC, Gaceta del Semanario Judicial de la Federación, Décima Época, t. IV, Libro 45, agosto 2017, p. 2920.
} 
ARTÍCULO TERCERO TRANSITORIO DE LA LEY NACIONAL DE EJECUCIÓN PENAL NO EXENTA AL JUEZ DE ANALIZAR -EN RESPETO AL PRINCIPIO DE RETROACTIVIDAD BENIGNA EN MATERIA PENAL- LAS DISPOSICIONES DEL CÓDIGO PENAL FEDERAL Y DE LA LEY NACIONAL DE EJECUCIÓN PENAL, PARA ESTABLECER SI EXISTE EN ÉSTA ALGUNA QUE REPORTE MAYOR BENEFICIO PARA EL SENTENCIADO QUE SOLICITA DICHO PRIVILEGIO PRELIBERACIONAL ${ }^{54}$; LIBERTAD ANTICIPADA PREVISTA EN LA LEY NACIONAL DE EJECUCIÓN PENAL. AL INVOLUCRAR ESTE BENEFICIO PRELIBERACIONAL EL DERECHO HUMANO DE LA LIBERTAD, SU NATURALEZA PROCESAL NO ES OBSTÁCULO PARA APLICARSE RETROACTIVAMENTE A FAVOR DEL GOBERNADO $^{55}$.

En este mismo ámbito sobresale la tesis por contradicción publicada el día 13 de abril de 2018, y por consiguiente obligatoria a partir del día 16 del mismo mes y año, con el rubro, LIBERTAD ANTICIPADA. LA APLICACIÓN DE LA LEY NACIONAL DE EJECUCIÓN PENAL A SENTENCIADOS EN EL SISTEMA MIXTO NO ESTÁ RESTRINGIDA POR LOS ARTÍCULOS TRANSITORIOS CUARTO DE LA REFORMA CONSTITUCIONAL PUBLICADA EN EL DIARIO OFICIAL DE LA FEDERACIÓN EL 18 DE JUNIO DE 2008 Y TERCERO DE LA LEGISLACIÓN CITADA (APLICACIÓN DE LOS PRINCIPIOS DE RETROACTIVIDAD DE LEY BENÉFICA Y PRO-PERSONA ${ }^{56}$.

Como podemos observar, los cuatro criterios señalados contienen destellos en favor de la retroactividad procesal penal en beneficio del reo, aunque sea únicamente para los sentenciados. Esto constituye, sin lugar a dudas, un gran avance, pues se toma como base de su aplicación, el principio de retroactividad en beneficio que opera en materia penal y el principio hermenéutico de derechos humanos pro persona, situación que se desprende, de manera especial, de la citada tesis por contradicción mencionada en el párrafo anterior. No obstante, este gran avance, entre los argumentos se alcanza a leer el viejo discurso de siempre, que se trata de derechos sustantivos como es el caso de la libertad anticipada y la libertad preparatoria y no de cuestiones meramente procesales.

Ahora bien, analizando el concepto de retroactividad procesal penal en beneficio del reo desde el contexto de otros países, debemos destacar el caso de Argentina, que en el Código Procesal de la Nación aprobado por la ley 27.063, establece en su artículo 11 la aplicación retroactiva de la ley procesal cuando favorezca al imputado, y además en su artículo 318 inciso e) contempla la revisión de la sentencia condenatoria firme cuando: Corresponda aplicar retroactivamente un cambio en la legislación que favorezca al condenado $o^{57}$, es decir, aun estando ante una sentencia que ha causado ejecutoria, puede revisarse cuando exista una ley que favorezca al condenado, aun siendo de carácter procesal.

\footnotetext{
${ }^{54}$ Tesis 2014835 I.7o.P.86 P TCC, Gaceta del Semanario Judicial de la Federación, Décima Época, t. IV, Libro 45, agosto 2017, p. 2917.

${ }^{55}$ Tesis I.7o.P.84 P TCC, Gaceta del Semanario Judicial de la Federación, Décima Época, t. IV, agosto de 2017, p. 2918

${ }^{56}$ Tesis por contradicción: PC.I.P. J/43 P (10a.), 2016600, Semanario Judicial de la Federación, Décima Época, Plenos de Circuito, publicación, viernes 13 de abril de 2018.

${ }^{57}$ Código Procesal Penal de la Nación (2014), [en línea], disponible en: http://www.afip.gov.ar/Institucional/boletinImpositivo/documentos/CODIGOPROCESALPENALDELANACION.pdf, [consultado el 18 de septiembre de 2018].
} 
Por su parte, también la doctrina internacional robustece esta última postura, pues Carlos Enrique Llera nos dice que:

la aplicación retroactiva es lícita en aquellos casos en que a nadie perjudica. Es más, se ha considerado que no sólo es lícita sino debida, en aquellos casos en que, sin perjudicar a nadie, alguien sale beneficiado [...] No existe mayor diferencia entre irretroactividad procesal penal y retroactividad penal, pues ambas se relacionan con el control sobre la arbitrariedad en el ejercicio del poder penal. [...] el principio de favorabilidad debe operar para garantizar la aplicación de la norma más favorable, sin que en materia penal pueda hacerse distinción entre normas sustantivas y normas procesales que resulten más benéficas al procesado [...]. En el caso en que la norma procesal resulte más favorable al imputado, deberá aplicarse ésta aun a los procesos en trámite [...] la ley procesal penal puede ser aplicada a procesos que ya estaban en marcha con anterioridad a su sanción, siempre que esta nueva ley no importe de ninguna manera una situación más gravosa para el imputado. ${ }^{58}$

En el contexto de los tribunales internacionales de derechos humanos, podemos observar la sentencia dictada por la misma CORTEIDH el 30 de octubre de 2008, en el caso Bayarri vs. Argentina ${ }^{59}$, en el cual concluyó una aplicación inmediata de las nuevas leyes procesales por ser más benigna en un caso de prisión preventiva. Es decir, a criterio de dicho organismo, si al momento en que se lleva a cabo una etapa procesal se encuentra vigente una nueva norma adjetiva que viniera a remplazar a una anterior o que beneficiara más a la persona que otra vigente al momento de la comisión del ilícito, se podría aplicar al caso en concreto y en beneficio del procesado.

Por lo que no es necesario que la norma procesal aplicable deba estar vigente al momento de la comisión del ilícito, ya que es más que suficiente que esté vigente al momento de agotarse la respectiva etapa procesal, pues los procesos se regulan por sus fases y etapas, así como por las normas reguladoras, por lo que no afecta el principio de legalidad, siendo la única manera en que podría afectarlo si se pretendiera aplicar una vez ya concluida la etapa procedimental.

Otra prueba de lo anterior, en el sentido de que en el derecho internacional en sus últimas instancias, en vía jurisdiccional, se opta por la aplicación de la retroactividad procesal penal en beneficio del reo, lo es la resolución de la precitada CORTEIDH de fecha 30 de enero de 2014, en la cual resolvió el caso Liakat Ali Alibux VS Suriname ${ }^{60}$, en la que se establece la posibilidad de acceso a las partes a una instancia de apelación de manera posterior a la conclusión de todas las etapas procesales que existían en ese momento en vigor, ya que incluso en dicho caso en concreto se reformó una ley, en la cual se establecía un recurso de apelación que no estaba previsto con anterioridad, y se instauró como cláusula transitoria que todas las personas que hubieran sido condenadas con anterioridad, tenían un plazo para hacer valer tal recurso a pesar de que la sentencia haya causado estado, o de que incluso, se haya compurgado la condena, pues en dicha sentencia se reflexionó:

\footnotetext{
${ }^{58}$ Llera, op. cit. nota 47.

${ }^{59}$ CORTEIDH. (2008), Caso Bayarri vs. Argentina, Sentencia del 30 de octubre, Serie C No. 187 [en línea], disponible en: http://www.corteidh.or.cr/docs/casos/articulos/seriec187esp.pdf, [consultado el 20 de septiembre de 2018].

${ }^{60}$ CORTEIDH (2014), Caso Liakat Ali Alibux vs. Suriname, 30 de enero, [en línea], disponible en: http:// www.corteidh.or.cr/CF/Jurisprudencia2/busqueda_casos_contenciosos.cfm, [consultado el 20 de septiembre de 2018].
} 
amén de considerar de que la previsión del art. $9^{\circ}$ apunta claramente a la legislación sustantiva, toma nota especialmente de que en los Estados partes de la región la tendencia conteste en lo referente a la ley procesal penal es la vigencia del principio tempus regit actum. Ni la aplicación hacia adelante de una norma procesal nueva está vedada ni la aplicación retroactiva de una condición procesal eventualmente más favorable a una etapa precluida es mandatoria. ${ }^{61}$

De lo que se desprende que, incluso, en el contexto internacional existe, además de la doctrina, legislación que establece reformas en materia procesal, como lo es un recurso de apelación, las cuales pueden ser aplicadas de manera retroactiva para todos los casos que obraron en el pasado y que incluso ya habían causado estado.

\section{Continuando con la resolución mencionada, la CORTEIDH estableció:}

a diferencia de las normas penales sustantivas, en las que el patrón de aplicación es el momento de la comisión, en las normas procesales debe tomarse como referencia el momento en el que tiene lugar el acto procesal, de tal modo que "los actos que conforman el procedimiento se agotan de acuerdo a la etapa procesal en que se van originando y se rigen por la norma vigente que los regula [...] al ser el proceso una secuencia jurídica en constante movimiento, la aplicación de una norma que regula el procedimiento con posterioridad a la comisión de un supuesto hecho delictivo no contraviene per se, el principio de legalidad. ${ }^{62}$

Ahora bien, por lo que se refiere al sistema jurídico europeo, específicamente en relación con Francia, se ventiló el Asunto C-650/13, en donde un ciudadano privado de su derecho de sufragio activo y pasivo con carácter indefinido como consecuencia accesoria de una condena por delito de asesinato, solicitó al Tribunal de Justicia en vía prejudicial analizara si le era aplicable la determinación de su Estado sobre la privación del derecho o si le era aplicable una norma posterior con base en el artículo 49 de la Carta de Derechos Fundamentales de la Unión Europea, relativo al derecho a la retroactividad de la ley penal más favorable, resolución que estableció:

el Sr. Delvigne podría, en efecto, encontrar remedio por dos vías distintas y, en el fondo, alternativas: Por un lado, mediante la apreciación de que el Derecho penal que le ha sido -y le continúa siendo-efectivamente aplicado vulnera el derecho de sufragio en las elecciones al Parlamento Europeo (artículo 39 de la Carta). Por otro lado, mediante la apreciación alternativa de que, en todo caso, el Derecho penal posterior, que no le ha sido aplicado, debiera haberlo sido en coherencia con la garantía incorporada al artículo 49 de la Carta (derecho a la retroactividad de la ley penal más favorable). ${ }^{63}$

${ }^{61}$ Martínez, Diego (2014), "Retroactividad de la ley procesal penal. Juzgamiento a través de fueros especiales. Derecho al recurso", InfoJus, Sistema Argentino de Información Jurídica, Jurisprudencia Anotada, Argentina, $\mathrm{p} \mid .323$ y ss.

${ }^{62}$ CORTEIDH (2014), Caso Liakat Ali Alibux vs. Suriname, op. cit. nota 62.

${ }^{63}$ Asunto C650/13 Thierry Delvigne contra Commune de Lesparre Médoc y Préfet de la Gironde [Petición de decisión prejudicial planteada por el tribunal d'instance de Bordeaux (Francia)], Conclusiones del abogado general Pedro Cruz Villalón, presentadas el 4 de junio de 2015, [en línea], disponible en: http://curia.europa.eu/juris/document/document.jsf;jsessionid=9ea7d2dc30dd48a30fed062648fabb41d8d942cd0463. e34KaxiLc3qMb40Rch0SaxyNchz0?text $=\&$ docid $=164740 \&$ pageIndex $=0 \&$ doclang $=E S \&$ mode $=l$ st\&$\operatorname{dir}=\& o c c=$ first $\&$ part $=1 \& c i d=916171$, [consultado el 20 de septiembre de 2018]. 
De lo que se desprende que, a partir de dichos criterios y parámetros establecidos en el derecho convencional, se puede determinar la legalidad de la aplicación de la retroactividad en materia procesal penal en beneficio del reo $^{64}$.

Ahora bien, la nuevamente citada CONVENCIÓNADH en su artículo 29, inciso b) establece; Artículo 29.- Normas de interpretación. Ninguna interpretación de la presente Convención puede ser interpretada en el sentido de: [...] b) limitar el goce y ejercicio de cualquier derecho o libertad que pueda estar reconocido de acuerdo con las leyes de cualquiera de los Estados Partes o de acuerdo con otra convención en que sea parte uno de dichos Estados. [... $]^{65}$. Cabe destacar igualmente, que en el artículo $1^{\circ}$ numeral 1 de esta Convención, la obligación de los Estados Partes para respetar los derechos y libertades reconocidos en ella y a garantizar su libre y pleno ejercicio a toda persona que esté sujeta a su jurisdicción, sin discriminación alguna por motivos de raza, color, sexo, idioma, religión, opiniones políticas o de cualquier otra índole, origen nacional o social, posición económica, nacimiento o cualquier otra condición social. Inclusive, en su artículo $2^{\circ}$ establece la obligación de adoptar disposiciones de derecho interno para garantizar y hacer efectivos esos derechos y libertades.

A su vez, el Pacto Internacional de Derechos Civiles y Políticos del 19 de diciembre de 1966, ratificado por México el 23 de marzo de $1981{ }^{66}$ y publicado en el Diario Oficial de la Federación el 20 de mayo de $1981^{67}$, establece en su artículo 15, numeral 1: Nadie será condenado por actos u omisiones que en el momento de cometerse no fueran delictivos según el derecho nacional o internacional. Tampoco se impondrá pena más grave que la aplicable en el momento de la comisión del delito. Si con posterioridad a la comisión del delito la ley dispone la imposición de una pena más leve, el delincuente se beneficiará de ello ${ }^{68}$.

No obstante que vemos en el ámbito internacional una clara apertura para poco a poco ir aplicando el principio de legalidad y retroactividad de la ley procesal penal en favor del reo (imputado, procesado, sentenciado), los tribunales federales de nuestro país asumen posiciones contradictorias. Pues, no obstante, la reforma constitucional del 10 de junio de 2011, donde destaca el compromiso de aplicar el principio pro homine, el Pleno de la SCJN el 25 de abril de 2014, da un giro de $180^{\circ}$, y emite una ejecutoria relativa a la contradicción de tesis 293/2011. Décima Época, Gaceta del Semanario Judicial de la Federación. 24985, con el rubro ${ }^{69}$ : DERECHOS HUMANOS CONTENIDOS EN LA CONSTITUCIÓN Y EN LOS TRATADOS INTERNACIONALES. CONSTITUYEN EL PARÁMETRO DE CONTROL DE REGULARIDAD CONSTITUCIONAL, PERO

${ }_{64} C f r$ artículo 49, numeral 1, de la Carta de los Derechos Fundamentales de la Unión Europea, en: [en línea], disponible en: http://www.derechoshumanos.net/normativa/normas/europa/CDFUE/CartaDerechosFundamentalesUnionEuropea-v2007.htm, [consultado el 26 de septiembre de 2018].

${ }^{65}$ Convención Americana, op. cit. nota 7.

${ }^{66}$ Pacto Internacional de Derechos Civiles y Políticos del 19 de diciembre de 1966. Disponible en línea: $h t$ tps://treaties.un.org/Pages/ViewDetails.aspx?src $=$ TREATY\&mtdsg_no $=I V-3 \&$ chapter $=4 \&$ clang $=$ en. (Consultado el 24 de septiembre de 2018).

${ }^{67}$ Compendio de tratados internacionales sobre derechos humanos (2013), op. cit., nota 9, p. 13.

${ }_{68}$ Pacto Internacional de Derechos Civiles y Políticos. Diciembre de 1966, [en línea], disponible en: https://www.ohchr.org/sp/professionalinterest/pages/ccpr.aspx, [consultado el 26 de septiembre de 2018]. El énfasis es nuestro.

${ }^{69}$ Tesis por contradicción 293/2011, Décima Época, Pleno, Gaceta del Semanario Judicial de la Federación, 24985, Tomo I. Pág. 96. 
CUANDO EN LA CONSTITUCIÓN HAYA UNA RESTRICCIÓN EXPRESA AL EJERCICIO DE AQUÉLLOS, SE DEBE ESTAR A LO QUE ESTABLECE EL TEXTO CONSTITUCIONAL.

En nuestra opinión, esta tesis constituye un gran retroceso en el ámbito de protección a los derechos humanos, pues establece la prevalencia de la Constitución sobre los tratados internacionales cuando exista contradicción entre estos, lo que conlleva a establecer que a pesar de que una norma o sentencia de carácter internacional pueda beneficiar a una persona en México - como lo podría ser el caso de la retroactividad procesal penal- debe prevalecer el criterio constitucional y en consecuencia optar por la inaplicabilidad de la norma internacional, aun siendo en beneficio de la persona, en este caso, del reo.

No obstante, esa postura que claramente va en contra del principio pro homine, en ese mismo mes de abril, del mismo año 2014, el Pleno de la SCJN emite otra tesis jurisprudencial P./J. 21/2014 (10a.). con el rubro ${ }^{70}$ : JURISPRUDENCIA EMITIDA POR LA CORTE INTERAMERICANA DE DERECHOS HUMANOS. ES VINCULANTE PARA LOS JUECES MEXICANOS SIEMPRE QUE SEA MÁS FAVORABLE A LA PERSONA, estableciendo que:

\begin{abstract}
Los criterios jurisprudenciales de la Corte Interamericana de Derechos Humanos, con independencia de que el Estado Mexicano haya sido parte en el litigio ante dicho tribunal, resultan vinculantes para los Jueces nacionales al constituir una extensión de la Convención Americana sobre Derechos Humanos, toda vez que en dichos criterios se determina el contenido de los derechos humanos establecidos en ese tratado. La fuerza vinculante de la jurisprudencia interamericana se desprende del propio mandato establecido en el artículo 1o. constitucional, pues el principio pro persona obliga a los Jueces nacionales a resolver cada caso atendiendo a la interpretación más favorable a la persona.
\end{abstract}

Con base en esta última tesis que es obligatoria, podemos decir que las jurisprudencias antes mencionadas emitidas por la CORTEIDH ${ }^{71}$, son de observancia vinculatoria para todas las autoridades del Estado mexicano.

\title{
IV. Conclusiones
}

No obstante que, desde que surge el Estado mexicano predomina la postura prohibitiva de la aplicación retroactiva de la norma procesal penal favorable al reo en cualquier etapa del proceso, establecida como regla general, por la interpretación al artículo 14 de la CPEUM, desde el pleno y los tribunales colegiados de circuito del poder judicial de la federación. Postura que, como ya lo señalamos, en nuestra opinión contraviene lo dispuesto por este mismo precepto constitucional, toda vez que éste permite la aplicación retroactiva de la ley en beneficio de las personas sin hacer distinción entre normas sustantivas o adjetivas.

No cabe duda de que, a partir de las reformas en materia de derecho de amparo y de derechos humanos del 6 y 10 de junio de 2011, con base, desde luego en el dere-

\footnotetext{
$\overline{70}$ Tesis jurisprudencial P./J. 21/2014 (10a.), Décima Época, Pleno, Libro 5, abril de 2014, Gaceta del Semanario Judicial de la Federación, Tomo I. p. 204.

${ }^{71}$ Además, desde el 16 de diciembre 1998, México depositó el instrumento de aceptación de la competencia litigiosa obligatoria de la CORTEIDH, ante la secretaría de la Organización de Estados Americanos (OEA).
} 
cho constitucional y convencional, poco a poco esa postura prohibicionista ha venido cambiando.

Efectivamente, esas reformas constitucionales se confrontan abiertamente con dichas posturas tan radicales y, estas a su vez, con el propio principio pro homine, con base en el cual todas las autoridades deben actuar con el criterio que más favorezca o proteja a la persona, sea que se encuentre en una norma de derecho interno o internacional.

Durante este trabajo se demostró que, los tribunales federales al continuar insistiendo en seguir aplicando tradicionalmente la postura prohibicionista basada solamente en el derecho positivo, se incurría, al mismo tiempo, en una reiterada violación, no solamente frente al principio de legalidad y retroactividad, sino también frente a los derechos humanos del debido proceso y seguridad jurídica, y en particular del principio pro homine.

Con esta investigación que abarcó una rápida mirada histórica del principio de legalidad y retroactividad desde el nacimiento del Estado constitucional de derecho, así como su evolución en los principales documentos constitucionales de nuestro país, podemos, tal vez explicarnos la postura prohibitiva tan rígida que adoptaron los tribunales federales sobre la irretroactividad procesal penal en beneficio de la persona. Pero, de la misma manera, el análisis, descripción, comparación y síntesis que hicimos de la doctrina, la legislación de otros países y, sobre todo, de la jurisprudencia emitida por los tribunales internacionales de derechos humanos, nos permitió darnos cuenta de la apertura que en ese ámbito está teniendo la aplicación del principio de legalidad y retroactividad en el derecho procesal penal cada vez más protector a los derechos humanos de la persona.

Por otra parte, la búsqueda y posterior análisis que hicimos de los diferentes criterios jurisprudenciales emitidos por los tribunales federales de nuestro país, antes y después de las mencionadas reformas constitucionales, nos permitió darnos cuenta del cambio de esa postura prohibicionista tan radical, gracias a la influencia que han tenido los tribunales internacionales de derechos humanos.

Tuvimos oportunidad, también, de percatarnos de la intención del Pleno de la SCJN, pues con la tesis por contradicción 293/2011, se pretendió, sin lugar a dudas, volver a esa práctica prohibicionista del principio que nos ocupa; sin embargo, derivado del voto razonado que emitió en contra el ministro José Ramón Cossío Díaz, provocó, de alguna manera que, a pesar de esa tesis, se emitiera otra en el mismo mes de abril de 2014, estableciendo que, aun cuando hubiera contradicción entre una norma constitucional y una norma convencional, tendría las autoridades la obligación de realizar la ponderación para aplicar la norma más benéfica a la persona ${ }^{72}$. Pero, el cambio que consideramos más sobresaliente de parte del Pleno de la SCJN fue la adopción de la tesis donde se estableció que serían vinculatorias para las autoridades mexicanas, todas las sentencias emitidas por la CORTEIDH, haya o no tenido parte en ese litigio el Estado mexicano. Esto sin lugar a duda, constituye un parteaguas en el derecho constitucional y convencional de nuestro país.

O sea, podemos decir que, mientras en la jurisprudencia interna y en la jurisprudencia internacional avanzamos a paso lento pero seguro sobre el desarrollo y adopción del principio de legalidad y retroactividad en materia procesal penal en beneficio del reo,

\footnotetext{
${ }^{72}$ Cfr. Cossío Díaz, José Ramón (2013), "Las trampas del consenso", [en línea], disponible en: https://www. nexos.com.mx/? $p=15502$, [consultado el 26 de septiembre de 2018].
} 
en la legislación penal interna aparentemente no sucede lo mismo, pues el artículo 487, fracción II, del Código Nacional de Procedimientos Penales ${ }^{73}$, se refiere a la aplicación de dicho principio solamente tratándose del sentenciado: Cuando una ley se derogue, o se modifique el tipo penal o en su caso, la pena por la que se dictó sentencia o la sanción impuesta, procediendo a aplicar la más favorable al sentenciado, pero de ninguna manera contempla expresamente la aplicación del precitado principio en el caso del proceso penal. Sin embargo, debemos estar atentos al contenido del artículo 12 del mismo ordenamiento legal, cuando establece que los órganos jurisdiccionales deberán dictar sus resoluciones con base en los principios de legalidad y debido proceso y, [...] con apego estricto a los derechos humanos previstos en la Constitución, los Tratados y las leyes que de ellos emanen. Lo cual significa que, en cualquier caso, se deben tener siempre presente las jurisprudencias internas e internacionales que hemos venido refiriendo anteriormente. Aunque, lo más conveniente sería que, a fin de evitar mayores confusiones y contradicciones, se legislara a ese respecto para establecer de una manera clara y precisa los parámetros o criterios de aplicación del principio de legalidad y retroactividad en materia procesal penal más benéfico a la persona, siempre basados en el principio pro homine.

Por todo lo antes expuesto, podemos decir que en este trabajo se alcanzaron plenamente los objetivos que nos trazamos en un inicio. Asimismo, se dio amplia respuesta a las preguntas que se formularon derivadas del planteamiento del problema y, sobre todo, se demostró la hipótesis que formulamos.

\section{Fuentes de consulta}

\section{Libros}

CARBonell, Miguel (2015), El ABC de los derechos humanos y del Control de Convencionalidad, $2^{\mathrm{a}}$ Ed. UNAM, México, Porrúa.

y Salazar, Pedro (coords. 2012), La Reforma Constitucional de Derechos Humanos. Un nuevo paradigma, México, Porrúa-UNAM.

Compendio de tratados internacionales sobre derechos humanos (2013), $1^{\text {a }}$ Ed. México, Ediciones Jurídicas LopMOn.

Ferrajoli, Luigi (2006), Sobre los Derechos Fundamentales y sus Garantías, Trad. Miguel Carbonell, Antonio de Cabo Gerardo Pisarello, Universidad de Roma III, Italia, México, Comisión Nacional de los Derechos Humanos.

(2002), Derechos y Garantías. La Ley del más débil, Prol. Perfecto Andrés Ibañez, Roma, Italia, Trotta.

Fix-Zamudio, Héctor y FiX-Fierro, Héctor (2009), “Articulo 14”, en: Miguel Carbonell, Miguel (coord..), Constitución Política de los Estados Unidos Mexicanos, comentada y concordada, México, Porrúa, ed. 29, Tomo I.

Fix-Zamudio, Héctor y Valencia Carmona, Salvador (2009), Derecho Constitucional Mexicano y comparado, $6^{\mathrm{a}}$ Ed. México UNAM, PORRÚA.

\footnotetext{
${ }^{73}$ Código Nacional de Procedimientos Penales (2014), [en línea], disponible en: http://www.diputados.gob.
} $m x /$ LeyesBiblio/, [consultado el 27 de septiembre de 2018]. 
García Máynez, Eduardo (2013), Introducción al Estudio del Derecho, 64º ed. México Porrúa.

Gellinek, Georg (2000), La Declaración de los Derechos del Hombre y del Ciudadano, Traducción y estudio preliminar de Adolfo Posada, México, Universidad Nacional Autónoma de México.

Silva Meza, Juan N. (Coord.) (2018), "Derechos Humanos parte general" en: Compilación y Sistematización de Tesis de la SCJN, $5^{\text {a }}$ reimpresión, México, Sistema Bibliotecario de la Suprema Corte de Justicia de la Nación.

Tena Ramírez, Felipe (2008), Leyes Fundamentales de México 1808-2005, $25^{\mathrm{a}}$ ed. México, Porrúa.

Zaffaroni, Eugenio Raúl (2000), "Derechos Humanos y sistemas penales en América Latina", en: Criminología crítica y control social. El poder punitivo del Estado, Argentina, Ed. Juris.

\section{Artículos}

Asunto C650/13 Thierry Delvigne contra Commune de Lesparre Médoc y Préfet de la Gironde [Petición de decisión prejudicial planteada por el tribunal d'instance de Bordeaux (Francia)] Conclusiones del Abogado General PEDRO CRUZ VILLALÓN presentadas el 4 de junio de 2015, [en línea], disponible en: http://curia.europa. $\mathrm{eu} /$ juris/document/document.jsf;jsessionid=9ea7d2dc30dd48a30fed062648fabb41d8d942cd0463.e34KaxiLc3qMb40Rch0SaxyNchz0?text=\&docid=164740\&pageIndex $=0 \&$ doclang $=E S \&$ mode $=1$ st\&dir $=\&$ occ $=$ first \&part $=1 \&$ cid $=916171$

Aguilera Portales, Rafael Enrique y López Sánchez, Rogelio (2011), Los derechos fundamentales en la teoría garantista de Luigi Ferrajoli, México, Instituto de Investigaciones Jurídicas de la UNAM.

Barbosa Castillo, Gerardo (2005), "Principio de legalidad y proceso penal", Derecho Penal y Criminología, Vol. 26, No 78, Universidad Externado de Colombia.

Cossío Díaz, José Ramón (2013), "Las trampas del consenso”, [en línea], disponible en: https://www.nexos.com.mx/?p=15502

FerRAJOLI, Luigi (2011), "El constitucionalismo garantista. Entre paleo-iuspositivismo y neo-iusnaturalismo". Doxa, Cuadernos de Filosofía del Derecho, 34, pp.311-360, [e, línea], disponible en: https://doxa.ua.es/article/view/2011-n34-constitucionalismo-principialista-y-constitucionalismo-garantista

Guevara B., José A. (2013), "La prohibición de la aplicación retroactiva de la ley", en: Derechos Humanos en la Constitución: Comentarios de jurisprudencia constitucional e interamericana, tomo II, México, Suprema Corte de Justicia de la Nación Suprema Corte de Justicia de la Nación.

Huerta, Carla (s.a.), Retroactividad en la Constitución, [en línea], disponible en: https:// archivos.juridicas.unam. mx/www/bjv/libros/5/2389/19.pdf 
LLERA, Carlos Enrique (2015), "Doctrina del día: la ley procesal más benigna. A propósito del Código Procesal Penal de la Nación aprobado por la ley 27.063", [en línea], disponible en: http://thomsonreuterslatam.com/2015/06/doctrina-del-dia-la-ley-procesal-mas-benigna-a-proposito-del-codigo-procesal-penal-de-la-nacion-aprobadopor-la-ley-27-063-autor-carlos-enrique-llera/

Magaña de la Mora Juan Antonio (2004), El catálogo de delitos graves como norma sustantiva y no adjetiva, México, Supremo Tribunal de Justicia del Estado de Michoacán, Michoacán.

MarTínez, Diego (2014), "Retroactividad de la ley procesal penal. juzgamiento a través de fueros especiales. Derecho al recurso", InfoJus, Argentina, Sistema Argentino de Información Jurídica, Jurisprudencia Anotada.

PIQUÉ, María Luisa (2013), “Artículo 9. principio de legalidad y retroactividad", La Convención Americana de Derechos Humanos y su proyección en el Derecho Argentino, Argentina, Universidad de Buenos Aires.

\section{Legislación}

Carta de los Derechos Fundamentales de la Unión Europea (2007), [en línea], disponible en: http://www.derechoshumanos.net/normativa/normas/europa/CDFUE/CartaDerechosFundamentalesUnionEuropea-v2007.htm

Código Nacional de Procedimientos Penales (2014), [en línea], disponible en: http://www. diputados.gob.mx/LeyesBiblio/

Constitución Política de Los Estados Unidos Mexicanos del 5 de febrero de 1917, [en línea], disponible en: http://www.diputados.gob.mx/LeyesBiblio/ref/cpeum.htm

Convención Americana Sobre Derechos Humanos. Noviembre 1969, [en línea], disponible en: https://www.oas.org/dil/esp/tratados_b-32_convencion_americana_sobre_derechos_humanos.htm

CORTEIDH (2014), Caso Liakat Ali Alibux VS Suriname, Sentencia de 30 de enero, Serie C No. 276, [en línea], disponible en: http://www.corteidh.or.cr/CF/Jurisprudencia2/busqueda_casos_contenciosos.cfm.

(2008), Caso Bayarri vs. Argentina. Sentencia del 30 de octubre, Serie C No. 187, [en línea], disponible en: http://www.corteidh.or.cr/docs/casos/articulos/seriec_187_esp.pdf

Declaración Universal de los Derechos Humanos. Diciembre 1948, [en línea], disponible en: http://www.onunoticias.mx/biblioteca/documentos-importantes/declaracion-universal-de-los-derechos-humanos/

Ley de Amparo. Reglamentaria de los artículos 103 y 107 de la Constitución Política de los Estados Unidos Mexicanos, [en línea], disponible en: http://www.diputados. gob.mx/LeyesBiblio/pdf/LAmp_150618.pdf

Pacto Internacional de Derechos Civiles y Políticos del 19 de diciembre de 1966, [en línea], disponible en: https://treaties.un.org/Pages/ViewDetails.aspx?src=TREATY\&mtdsg_no=IV-3\&chapter $=4 \&$ clang $=$ en 
Pacto Internacional de Derechos Civiles y Políticos. Diciembre, 1966, [en línea], disponible en línea: https://www.ohchr.org/sp/professionalinterest/pages/ccpr.aspx

Reforma constitucional del 6 de junio de 2011, en materia de derecho de amparo publicada en el Diario Oficial de la Federación (DOF), [en línea], disponible en http:// www2.scjn.gob.mx/red/constitucion/6Junio.html. eforma constitucional del 10 de junio de 2011, en materia de derechos humanos publicada en el DOF, disponible en: http://www2.scjn.gob.mx/red/constitucion/10Junio.html 